\section{BEHAVIOUR OF PIGS}

T the course of experimental work of a nutritional 1 and physiological character at the National Institute for Research in Dairying, R. Braude has noted some interesting features about the behaviour of pigs (Bull. Animal Behaviour, No. 6 ; January 1948). These observations have been recorded without any attempt to fit them into the framework of existing theories of behaviour, and, in the words of Dr. E. S. Russell, they merely "serve to illustrate what is the most characteristic feature of behaviour, namely, that the animal tries or strives to do something specific, that it seems to achieve some end, to satisfy some need".

On one occasion a wooden block resembling a sow with two rows of rubber teats fitted at the approximate spot was put into the farrowing pen. It was placed as near as possible to a sow which was farrowing. Not one of the fourteen piglets born on this occasion showed any interest whatsoever in the dummy teats, while all were keenly interested in the real teats, and as usual fought for access to them.

Another observation concerns the behaviour of piglets in suckling usually from the same teat. Donald has stated that "this ability must be founded mainly on sight, with some capacity to recognize the foel of a nipple playing a secondary part. Hearing may be disregarded, and so may a sense of smell, for pigs placed with a foster mother will, if they are able, take up the position they had on their original mother." From the start it seems to be of importance to the piglets to obtain a correct position on the udder. The quality of the teats varies to such an extent that it is not surprising that in the early stages of suckling the piglets are prepared to fight for access to the good ones and those successful occupy them permanently. The resultant growth-rate of the victors indicates the importance of this selection. With a small litter the best teats are soon discovered and continue to be sucked throughout lactation, while the poor ones are completely abandoned, and gradually dry off. With large litters some of the piglets never secure the chance of settling down at a good teat, and this fact seems to be mainly responsible for the usual one or two 'runts' in a large litter.

The effects of massaging the udder by the piglets just before the actual suckling have also been observed. With cows, the composition of the milk obtained depends on whether the udder has been previously stimulated or not, while in pigs there is evidence that the milk obtained by draining it off is only half as rich in fat as that obtained by the young pigs suckling. That the controlling factor is of a hormonal nature has been confirmed by Kon, Thompson and Braude, and by means of 'Pitocin', a proprietary extract from the posterior lobe of the pituitary which contains the oxytocic principle, it is now possible to milk a sow in much the same way as a cow. To milk the sow after treatment with 'Pitocin' the sow' has to be roped. Here an interesting aspect of behaviour is shown. It is well known that a sow will struggle against roping and that once caught she will try to get rid of the rope. What she usually does, however, is to pull back with all her strength, and by so doing makes the noose only more secure. On the other hand, if she were to walk forward-and there is nothing to stop her doing so-the effectiveness of roping would be completely lost. For some unknown reason this never occurs. The explanation that she can see the holder of the rope in front of her and tries to back away from him has proved to be untrue. The holder of the rope has been concealed and two people have been placed behind the sow. Those behind have had to push with all their strength to make the sow step forward.

Other observations show that, once a sow has done a long walk to the piggery where the boar is kept, she seems to learn the route and needs little guiding on subsequent occasions. Sows usually keep to the road and are careful when leaving it, making sure that the path they are taking is safe for them.

Except when mating, two grown pigs brought together will fight each other until one establishes a complete supremacy; sometimes even death may result. Mixing young weaners from different litters invariably results in a fight; but these soon settle down together. On the whole, however, pigs like company, and cases have been known when separated pigs have had to be brought back to their mates because "they went in seclusion on what amounted to a hunger strike". It is also known that a strong pig will keep a weaker one away from the food trough, while in the pen the favourite place for sleeping is occupied by the stronger. On occasions when two lots of pigs are mixed together in one pen, the usual fight is followed by the relegation of the defeated to the dunging passage.

That pigs quickly become accustomed to new routines which have to be introduced into an experi. mental piggery is shown by the following. Pigs have to be weighed at frequent intervals, sometimes daily and at least once weekly. At first it is difficult to get them into the weighing pen; but, after a few times, they walk into it of their own accord as soon as the door of the weighing pen is opened. A clearer example of a conditioned reflex is quoted by Braude from Denmark. There, a certain pigman arrives at his piggery in the morning and, as his first job, rings a heavy bell. This was a signal for all the pigs in that piggery to get up and go out into the dunging passage to defecate and urinate. The procedure was repeated as regularly in the afternoon, and this practice kept the piggery clean.

Information on the feeding habits of pigs has also been collected and shows the pig is a selective feeder. The now well-known story of its liking for copper is re-told, together with further evidence which has been collected by experimental inquiry.

\section{NATURE AND CONSTITUTION OF GLASS}

$A^{T}$ $T$ the recent joint meeting of the International Commission on Glass and the Society of Glass Technology, a symposium was arranged having as a general title "Some Aspects of the Nature and Con. stitution of Glass". Fifteen papers, presented by American, British and Continental investigators, ranged widely over the subject and raised, in each of three sessions, lively and sustained discussions.

In an introduction to the series of papers, Prof. W. E. S. Turner reviewed the important historical developments of the subject and referred to the place of theory in glass technology. Whereas for some forty years or more Tammann's theory of glass as a supercooled liquid had done much to account for many of the properties of glasses, greater insistence was now being laid, as indicated in the paper "Solid 
Liquids" submitted by Dr. F. W. Preston (Butler, U.S.A.), on the elasticity and therefore solid character of glass, with a definite atomic structure like a crystalline material, although without the regular repetition of the structural units found in a crystal.

Mr. S. M. Cox (Sunderland), in his paper on "An Elementary Kinetic Theory of Dilute Silica Glass", developed further a kinetic theory he had previously outlined. He employed an ingenious short film to illustrate the movements of the atoms at different temperatures and to explain his concepts. He suggested that an important term in equations describing the variation of physical properties with temperature is the proportion of loosely linked oxygen atoms, and he showel that the equation for this proportion can be derived from a simple distribution of potential energy curves. Equations relating the electrical conductivity with temperature, and of viscosity with temperature, were derived, and it was shown that the calculated results compare favourably with known experimental data.

Dr. G. O. Jones (Oxford) stressed the view that the study of glass can make a great contribution to the theory of the liquid state and the theory of melting. He outlined the present state of knowledge of the property-temperature changes in the transformation range and indicated the need for experimental work designed to provide full thermodynamic data. He also emphasized the need for experimental work on the kinetics of the crystallization process in glasses, on the stabilization phenomena, on the chemical durability of very thin films, and on the need for a theory of viscosity which would include the delayed elasticity effect. In the discussion, Prof. A. Smekal (Darmstadt) referred to work in Germany during the last eight years, particularly to the electron microscope examination of fracture surfaces, and to substances which have their transformation ranges near the melting point.

Mr. J. E. Stanworth (Sheffield) reviewed recent ideas of glass from the point of view of their ionic structures, referring particularly to the use of the electro-negativity values of the elements as a guide to their behaviour in a glass structure, and to the unusual behaviour of lead, bismuth and thallium, three ions which can be introduced in large percentages into glasses because of their high deformabilities.

Dr. J. M. Stevels (Eindhoven) discussed the relation between the dielectric losses and the constitution of glass, first describing briefly the theory of Gevers and du Pre, and the manner in which the theory explains the formulæ of Strutt and von Schweidler for the dependence of loss angle on temperature and frequency, respectively. Dr. Stevels pointed out the need for measurements at temperatures approaching absolute zero, and then outlined his theory of the effect of composition on losses, developing an equation which agrees with known data at a frequency of about $10^{6}$ cycles per second.

Dr. S. P. Varma first presented a paper written in collaboration with Prof. W. A. Weyl (Pennsylvania State College), and also one by Dr. F. L. Jones and Dr. N. J. Kreidl (Rochester, N.Y.), both papers dealing with the optical properties in relation to constitution. Dr. Varma emphasized the fact that cations with electronic structure not of the noble gas type have bonding properties to neighbouring ions markedly different from corresponding noble gastype ions. A series of curves showing molar refraction against composition, for silicate and borate glasses, emphasized the high contribution of lead ions as compared with barium and strontium ions, and of zinc ions as compared with magnesium ions.

A paper by Mr. J. B. Murgatroyd (Greenford) (read by Dr. E. J. Gooding) described the delayed elastic effect in glass fibres and showed that this effect increases with decrease in fibre diameter. Some conclusions were made concerning the arrangement of the bonds in fibres, and the relation between the structure of chilled and liquid glass.

Mr. R. W. Douglas (Wembley) outlined a theory of viscosity for simple glasses, based on the idea that there are two equilibrium positions (separated by an energy barrier) for each oxygen atom, the application of a stress enabling the oxygen atom to move from one potential minimum to the other; together with the thermal agitation of the atoms, this movement can provide flow. An equation for viscosity derived from this theory was used to compare calculated with known data, and the conclusion drawn that in complex glasses other atoms than the oxygens (for example, the sodium atoms) are probably involved in the flow mechanism.

Dr. G. O. Jones also spoke on the flow of glass, with particular reference to temperatures below the transformation range; he described the experimental results of strain-time measurements, and suggested that a model representing accurately the observed values could be either a number of Maxwell models in parallel or Voigt models in series, using a suitable distribution of relaxation times. In the discussion, Prof. A. Smekal referred to the measurements in Germany of the rate of crack propagation, using ultrasonics, and to theoretical work showing that the Griffith flaw theory can explain the continuous distribution of relaxation times and elastic aftereffects.

\section{FORTHCOMING EVENTS}

(Meetings marked with an asterisk * are open to the public)

Monday, December 13

British MUSEUM (NATURAL History) (at the Royal Scottish Museum, Chambers Street, Edinburgh), at 5.30 p.m.-Mr. Douglas A.
Allan: "The Geology and Scenery of Scotland" (Swiney Lectures).* (Further Lectures will be given on December 15 and 17, January 17, 19,21, 24, 26 and 28.)

MANCHESTER LITERARY AND PHILOSOPHIOAL SOCIETY (in the Reynolds Hall, College of Technology, Manchester), at 5.30 p.m.Dr. E. Lind : "Cheshire Meres"."

UNIVERSITY OF LONDON (at the Institute of Education, Malet Street, London, W.C.1), at 5.30 p.m.-Mr. Corder Catchpool : "Education for International Understanding-Central Europe".*

\section{Tuesday, December 14}

SOCIETY OF ChEMical INDUSTRY, PLASTICs GrodP (at Gas Industry House, 1 Grosvenor Place, London, S.W.1), at 2.30 p.m.-Dr. D. D Eley : "Biological Polymers". (Members of the Biochemical Society are invited.)

ZOOLOGICAL SOCIETY OF LONDON (at the Zoological Gardens, Regent's Park, London, N.W.8), at 5 p.m.-Scientific Papers.

INSTITUTE OF PHYSICS, ELECTRONICS GROUP (at 47 Belgrave Square, London, S.W.1), at 5.30 p.m.-Dr. J. D. Craggs: "Some Limitations of Particle Counting with Electron Multipliers and Geiger Counters". INSTITUTION OF ELECTRIOAL ENGINEERS, RADIO SECTION (at Savoy Place, Victoria Embankment, London, W.C.2), at 5.30 p.m.-Discussion on "Frequency Modulation versus Amplitude Modulation" (to be opened by Mr. H. L. Kirke).

INSTITUTION OF NAVAL ARCHITECTS (joint meeting with the INSTITUTE OF MARINE ENGINEERS, at 85-88 The Minories, London, E.C.3), at 5.30 p.m.-Prof. L. C. Burrill: "Latest Developments in Reversible Propellers".

ILUUminating Engineering Societr (at the Lighting Service Bureau, 2 Savoy Hill, London, W.C.2), at 6 p.m.-Dr. J. N. Aldington : "The Gas Arc-a New Light Source".

INSTITUTION OF STRUCTORAI ENGINEERS, LANCASHIRE AND CHESHIRE BRANCH (at the College of Technology, Manchester), at
7 p.m.-Mr. R. A. Foulkes: "The Use of Light Alloys in Structures". 